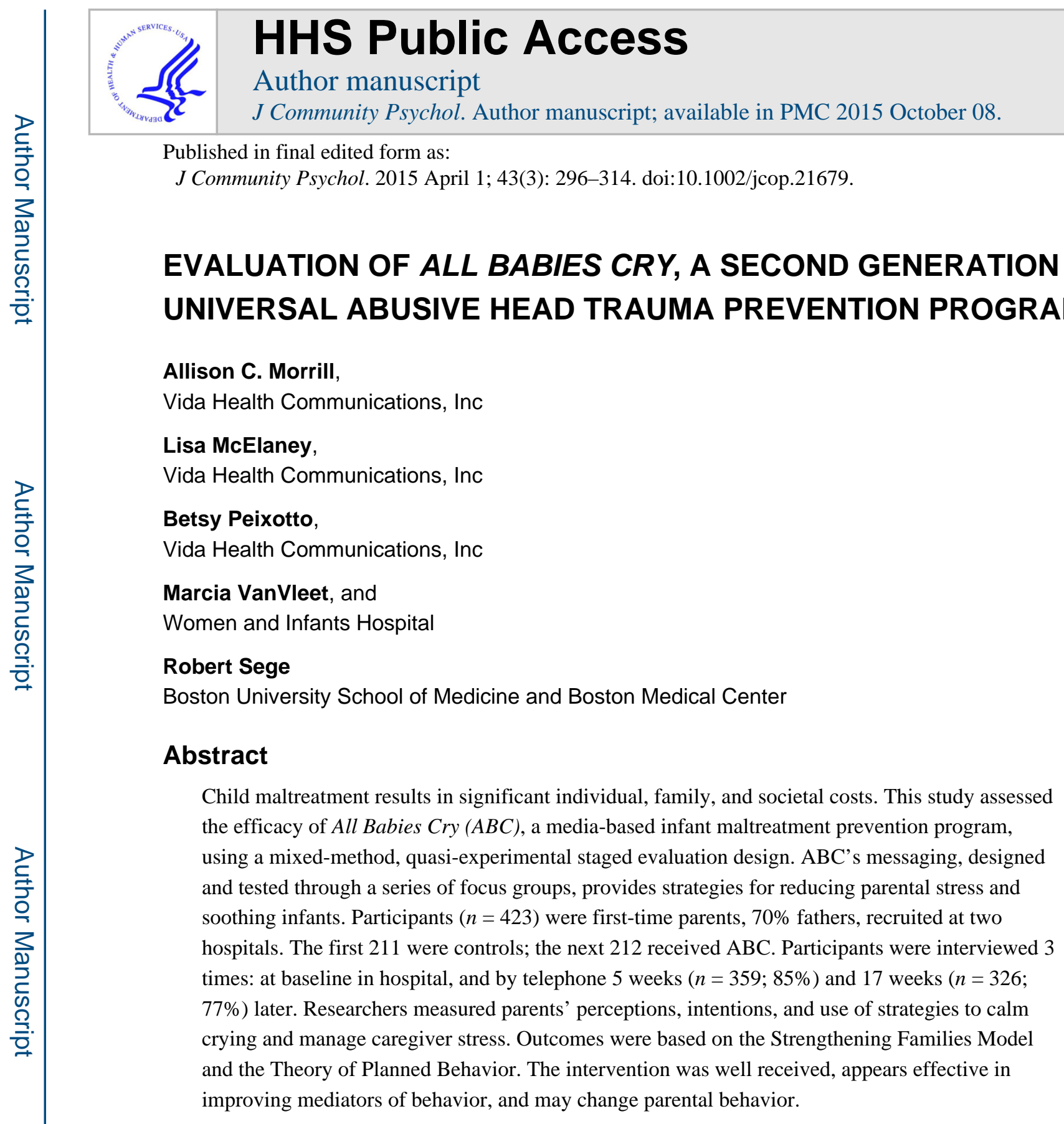

Child maltreatment results in significant individual, family, and societal costs. The Centers for Disease Control and Prevention (CDC) estimated that lifetime medical costs of child maltreatment reported in 2008 will be approximately $\$ 124$ billion with total societal costs reaching $\$ 585$ billion (Fang, Brown, Florence, \& Mercy, 2012). Maltreatment prevention within state child welfare agencies has become increasingly focused on building the specific family protective factors originally described by Horton and colleagues in 2003 (Horton, 2003; The Center for the Study of Social Policy, 2011). These protective factors, forming the basis of the Strengthening Families Approach (SFA), are as follows: nurturing and attachment, parental resilience, social connections, concrete support in times of need, and

Please address correspondence to: Lisa McElaney, Vida Health Communications, 50 Blue Hill Dr., Westwood, MA 02090. Lisa@vida-health.com. 
knowledge of parenting and child development and social and emotional competence of children (Figure 1). Research has established that when these factors are present in families, there is less likelihood of abuse and neglect (Daro \& Donnelly, 2002).

These factors also support early brain growth and may be associated with lifelong improvements in health (Shonkoff, Phillips, \& National Research Council (U.S.) Committee on Integrating the Science of Early Childhood Development, 2000) and are aligned with CDC's promotion of safe, stable nurturing relationships to prevent maltreatment (Alexander et al., 2013).

Considerable evidence in the literature points to the usefulness of Theory of Planned Behavior (TPB; Ajzen \& Fishbein, 1980) in understanding important influences on behavior. The TBP posits that behavior is predicted by a combination of beliefs about target behaviors, and those beliefs influence behavioral intentions and, ultimately, behavior (Ajzen $\&$ Fishbein, 1980; Figure 2). The theory has proven particularly useful in designing and evaluating health-promoting interventions (Ceccato, Ferris, Manuel, \& Grimshaw 2007).

Current maternity-based maltreatment prevention programs (Barr, Barr, et al., 2009; Barr, Rivara, et al., 2009; Dias et al., 2005; Midwest Childrens' Resource \& Junior League of Saint, 1995, 2005; National Center on Shaken Baby Syndrome, 2004, 2007) focus on the prevention of abusive head trauma (AHT; previously referred to as "shaken baby syndrome"), a condition that leads to significant disability and death among American infants younger than 1 year of age. In 2010, 600 U.S. infants younger than 1 year of age died of abuse, most from head trauma (U.S. Department of Health and Human Services, 2011). Men commit between $68.5 \%$ and $79 \%$ of all infant child abuse (Schnitzer \& Ewigman, 2005; Starling, Holden, \& Jenny, 1995; The Center for the Study of Social Policy, 2011). AHT occurs in all racial, ethnic, and socioeconomic groups (Riffenburgh \& Sathyavagiswaran, 1991; Sinal et al., 2000).

AHT may be preventable through education (Altman et al., 2011; Dias et al., 2005). Twentyfour states require maternity hospitals to provide AHT education (National Conference of State Legislators, 2012). The first generation of evidence-based educational media addressing AHT, developed between 1995 and 2007 (Barr, Barr, et al., 2009; Barr, Rivara, et al., 2009; Dias et al., 2005; Midwest Childrens' Resource \& Junior League of Saint, 1995, 2005; National Center on Shaken Baby Syndrome, 2004, 2007), was aimed primarily at mothers, and focused the attention on the effects of shaking, as a cause of brain damage and death (Altman et al., 2011; Barr, Barr, et al., 2009; Barr, Rivara, et al., 2009; Dias et al., 2005; Goulet et al., 2009). Infant crying is the only child-specific variable that has been linked consistently to the cycle of escalation that leads to inflicted injury (Barr \& Runyan, 2008; Davies \& Garwood, 2001; Lee, Barr, Catherine, \& Wicks, 2007).

All Babies Cry (ABC) is a theory-based infant maltreatment prevention program designed for use at the maternity bedside and at home, building on these earlier efforts. This report describes the evolution and design of $\mathrm{ABC}$, including a substantial formative research component, and the evaluation of the effect of its health communication and injury prevention messages on new parents. In developing $\mathrm{ABC}$, health communications specialists 
and instructional designers collaborated with injury prevention experts from the Massachusetts Department of Public Health (MDPH). Their aims were as follows: (a) develop content that would depict ways for assessing and mitigating parental stress in addition to demonstrations of infant crying behavior and soothing strategies; (b) design the media in modules so that it could be easily disseminated to all new parents shortly after birth; (c) appeal to fathers as well as mothers; and (d), ultimately, be effective in preventing injuries.

$\mathrm{ABC}$ builds on previous maternity unit-based maltreatment prevention efforts in several new ways:

- It promotes three SFA protective factors associated with a reduction in overall child abuse and neglect, specifically, parents' knowledge of parenting and child development, parental resilience, and social connectedness.

- Guided by the TPB, it seeks to not only increase viewers' use of the target behaviors for calming a crying infant and maintaining one's own composure but also enhance viewers' (a) belief that the target behaviors will work (perceived effectiveness), (b) belief that they have the ability to carry out the target behaviors (perceived behavioral control), and (c) plan to use the target behavior (behavioral control).

- Program content is informed by (a) formative research with parents, (b) published reports about infant crying as a trigger for abuse by perpetrators of AHT (Flaherty, 2006), and (c) observation of social worker-led therapy groups for men (all fathers) who had been convicted of domestic partner violence and who were asked about their responses to infant crying.

- $\quad \mathrm{ABC}$ 's pedagogical approach draws on principles of adult learning theory in recognizing different learning styles, and that adults have a range of learning experiences behind them, have developed individual strengths, and bring life experience to the learning; thus, compared to younger learners, they tend to be more goal-oriented, internally motivated and self-directed, and need to feel the topic is relevant and beneficial to themselves.

- $\mathrm{ABC}$ uses communication strategies purposefully designed to reach fathers as well as mothers in the target audience of new parents.

\section{FORMATIVE RESEARCH}

The program developers based the $\mathrm{ABC}$ content and approach on earlier work of the MDPH's "Shaken Baby" Prevention Initiative, which involved distribution of an "All Babies Cry" brochure by nurses at the maternity bedside. ABC developers first conducted extensive formative research, which included interviews of both expert and lay key informants and focus groups with expectant and new parents. The formative research methods and results are described below. Results were used to shape the learning objectives of $\mathrm{ABC}$, described at the end of this section. 


\section{Formative Methods}

1. Developers first conducted extensive interviews with 11 experts on child abuse prevention, family violence prevention and remediation, fatherhood, and stress management. Experts were affiliated with the MDPH injury prevention programs; the Responsible Fatherhood initiative; the Family Violence Prevention Fund; the Child Protection Program of Children's Hospital, Boston; Emerge-Counseling and Education to Stop Domestic Violence; and the Family Safety Project (Lowell, MA).

2. Prior to scripting, $\mathrm{ABC}$ developers also conducted key informant interviews with a diverse group of three fathers and seven mothers of newborns between the ages of 2 weeks and 6 months. The parents were recruited from the pediatrics practice at Boston Medical Center following approval from the Boston University Medical Center (BUMC) Institutional Review Board (IRB). Interview topics revolved around interviewees' prenatal understanding of infant crying patterns and their experiences with parental stress related to newborn crying and with successful soothing strategies.

3. Developers then assembled two parent focus groups to help shape program content and visual style. Participants were eight fathers (five first-time parents) who responded to fliers distributed at BUMC's pediatrics practice and advertisements on Craigslist. Measures in the focus group discussion guide included eight questions developed in response to the earlier key informant findings. The questions elicited fathers' observations about feelings and behaviors related to their current newborn's crying, as well as to recollections of experiences with older children.

4. Upon completion of a draft prototype of the media, developers submitted it to expert consultants for review, and then to two additional, naïve focus groups. Nine fathers and six mothers participated and were recruited from BUMC and Craigslist. The leader showed the prototype and asked participants about the following: when the best time(s) to receive this education would be; preferences for technology platforms; ways to ensure that the program would be appealing and helpful to fathers; suggestions for encouraging new parents to ask for help when they feel unsure or overwhelmed; and ways to show help-seeking and stress reduction behaviors as strengths and as part of developmentally supportive newborn care.

Interviews and focus groups were transcribed and audited by a second member of the formative research team. Transcripts of the focus groups were reviewed by members of the program development team, who independently extracted core ideas from the aforementioned themes. These formed the basis for subsequent instructional design and scripting.

\section{Formative Results}

Key informant interviews with parents identified a need for education materials featuring men as coequal caregivers during the newborn period. They also shaped the direction of subsequent focus group research conducted prior to scripting. Because there was consistency 
and substantial agreement among female key informants regarding recommended elements for parent education about infant crying and soothing, developers elected to populate subsequent focus groups with males.

The ABC developers identified several themes from the preproduction focus groups related to (a) the experience of stress related to infant crying, (b) preferred strategies for soothing infants (c) preferred strategies for soothing oneself when stressed by infant crying, (d) understanding of newborn brain development, (e) preferred sources for support and advice on handling newborn crying, (f) parents' perceptions of crying as an infant behavior rather than a reflection on parenting skill, and (g) desire for practical information, featuring demonstrations and advice from parents like themselves over information and warnings about maltreatment. Fathers frequently expressed frustration in regard to education about infant care: They felt that messages delivered in the hospital setting, in the general media, and on the Internet were directed exclusively at mothers.

Parents in the focus groups expressed a preference for media to be presented in discrete chapters to allow for easier navigation in moments of exhaustion or stress. They also suggested the following: the kinds of information they would like to see supported by evidence and data; content for graphs and charts; ways to best use humor, anecdote, and testimonial; and opportunities for animation and interaction. Parents also offered opinions about program length, modular design, voice-over narration, and musical score, and said they would appreciate reinforcement of program messages in accompanying print materials.

Although $\mathrm{ABC}$ was being designed as primary prevention directed at all new parents, program developers sought to increase the chances that its messaging and visual treatment would resound with parents at high risk for experiencing stress during the newborn period. To this end, ABC's script and health communication tactics were informed by first-hand accounts of AHT perpetrator's experiences published by Emalee Flaherty (2006). Additionally, in the script development phase, ABC developers sat in (as nonparticipant observers) on court-mandated, social worker-facilitated groups of convicted male perpetrators of domestic partner violence (who were also fathers, aged 18-78 years). Consistent with earlier research, this focus group members' accounts pointed to infant crying as a familiar trigger for child physical abuse and also revealed a lack of selfawareness about physiological and emotional indicators of mounting stress (Flaherty, 2006). Based on both the published and the observed testimonies of perpetrators of child or domestic partner abuse, $\mathrm{ABC}$ developers recognized a need to increase the proportion of program content directed at helping parents recognize biophysical and other signs of mounting stress attributable to infant crying or a combination of infant crying and exhaustion.

Responses to the prototype from parent participants led to developer decisions: to design the finished program so that it could be delivered in discrete doses beginning at the hospital maternity stay, and using the most readily accessible technology platforms, including mobile phones once home from the hospital; to include grandparents among $\mathrm{ABC}$ 's cast of real parents; to create a substantial companion booklet; to accentuate the need for new parents to build and use both traditional and novel support systems; to edit the program so that each 
scene could be linked to a protective factor within the SFA approach; and to feature practical demonstrations of infant care and stress management by fathers.

\section{Learning Objectives}

In four distinct video chapters, $\mathrm{ABC}$ situates explicit AHT prevention tactics within the broader context of a universal primer for new parents. Together documentary footage, real parent testimonies, humorous animations, graphical information, and an accompanying booklet convey program messages. Objectives of the educational program are as follows: (a) to foster attachment and healthy infant development by bolstering family strengths known to reduce infant maltreatment; (b) to improve parent responses to infant crying by visually depicting a wide variety of care strategies; and (c) normalize and mitigate parental stress by offering recommendations for identifying and reducing parental stress resulting from newborn care.

Because formative research and a review of the literature suggested that perpetrators of AHT tend not to recognize they are stressed until it is too late, $\mathrm{ABC}$ devotes one of its modules exclusively to parental self-care. Real parents describe their responses to stress and specific strategies for alleviating stress. These include: discussion of biophysical signs of mounting tension such as increased perspiration, heart rate, pressured speech or volume of speech, withdrawal from interaction, muscle tension, headache, repetitive nervous movements, and other physical symptoms of possible emotional dysregulation. The ABC self-care module further demonstrates specific strategies for ameliorating stress, emphasizing those strategies named most frequently by male participants in the project's formative research i.e.: placing the crying infant in a safe space and taking time to regroup; using physical exercise for stress reduction; sharing one's frustrations about infant crying with other new parents; communicating with one's partner about one's responses to the crying; enlisting and shaping the support of grandparents; skin-to-skin holding of infants by fathers; and more.

$\mathrm{ABC}$ is designed to engage both fathers and mothers. Men are featured on screen $70 \%$ of the time. Fathers demonstrate the majority of infant soothing strategies (swaddling, skin-to-skin holding, etc.). The evaluation oversampled men to determine the effect of $\mathrm{ABC}$ on men.

Evaluators of the $\mathrm{ABC}$ intervention hypothesized that parents who received the $\mathrm{ABC}$ intervention, compared to parents in the control condition, would

- execute a greater number and broader range of appropriate behaviors to reduce and cope with infant crying and assess and manage their own stress;

- have greater knowledge of parenting and child development, resilience, and social connection; and

- have greater belief in the efficacy of strategies for infant soothing and parental stress management, greater perceived ability to implement them, and greater intention to do so. 


\section{EVALUATION METHODS}

\section{Research Design}

To assess these hypotheses, evaluators selected a quasi-experimental design to obtain equivalent populations without exposing the control population to the intervention. In the first phase of the study, all participants were assigned to the control condition; at midpoint, the $\mathrm{ABC}$ intervention was implemented at both sites and therefore all further participants were in the intervention condition. The New England IRB reviewed and approved the protocol, as did each site's IRB.

\section{Participants}

Participants were 423 first-time parents of infants born at either recruitment site: a level I birth hospital with 1,377 births annually, and a level III birth hospital with 8,362 births annually. One parent per infant was eligible for enrollment. To achieve $70 \%$ male participation without overrepresenting single women, fathers and mothers were recruited sequentially ( 35 fathers, then 15 mothers). A parent was eligible if she or he had no previous children, expected to be living in the same home as their newborn, had to have a caregiving role at least some of the time, could understand and speak either English or Spanish, and had the ability to play a DVD. Parents were excluded if there was an open child protective case, or if the infant was born preterm ( $<37$ weeks gestation), at low birth weight ( $<5$ pounds at birth), or spent $>24$ hours in the neonatal intensive-care unit. Figure 3 diagrams the study population and recruitment.

\section{Procedures}

Recruitment-A hospital staff member approached all potential participants. The infant's mother facilitated paternal contact when necessary

Condition-Control participants received usual care, which at one site included one-onone AHT education with their nurse and state-mandated AHT education (comprising a DVD and handouts). The $\mathrm{ABC}$ intervention comprised (a) an 11-minute overview video for inhospital use, which introduces topics covered in the take-home components, and (b) a takehome package comprising a DVD with four brief skills-based modules and a 28-page booklet reinforcing messages in the media programs. Participants viewed the overview video in the hospital immediately after the baseline interview, and were then given the takehome package.

Data collection-Baseline interviews were conducted privately immediately after enrollment. Follow-up telephone interviews were conducted 5 and 17 weeks after baseline. For those in the intervention group, if, at 5 weeks, the parent said they had not yet reviewed the take-home package, the interview was deferred for approximately one week until they had reviewed the materials. Interviewers entered responses on laptop computers; no recordings were made. 
Evaluation measures included quantitative and qualitative behavioral outcomes and assessed three of the six SFA protective factors (Figure 1; Horton, 2003) and three measures based on the TPB (Ajzen \& Fishbein, 1980; Figure 2). All measures were by self-report and, except as noted, answer choices were closed-ended. Because they were tailored for this intervention, all were pretested by focus group participants to assess their psychometric properties for the target population. Where there was redundancy, the more reliable measure was used.

Behavior-A seven-day time frame was selected to avoid degradation of recall, and because newborn behavior changes rapidly.

- Appropriate strategies to calm a crying infant: Respondents were asked to identify all strategies that they expected to use (baseline) or used (follow-up) to calm their infant's crying. At follow-up they were asked how many times their baby had cried for no apparent reason, and how often in the past week they had used each strategy they had mentioned and each of seven target strategies portrayed in ABC (listed in Figure 4). Researchers coded the open-ended answers and calculated the number and variety of strategies used.

- Appropriate strategies to manage parental stress: At each follow-up interview, after a normalizing introductory statement, respondents were asked how many times they "reached a limit on the amount of crying they could tolerate."

Respondents were asked in an open-ended format to identify all strategies that they might (baseline) or did (follow-up) use to manage their stress. Next, they were asked how often in the past week they had used each self-identified strategy and each of five target strategies portrayed in ABC (listed in Figure 4). Researchers coded the open-ended answers, and calculated the number and type of strategies used.

- Self-reported change: Intervention parents were asked whether they had viewed the materials and, if so, whether they had done anything differently because of them. If so, they were asked to describe, in open-ended format, what they did differently.

Strengthening Families Model (SFM) Protective Factors-Researchers developed survey items that examined three of the SFM protective factors (Horton, 2003):

- Knowledge of parenting and child development: Participants rated their opinion (from "strongly disagree" to "strongly agree") on eight statements that were closely tailored to the program content, e.g., "If I pick up my baby every time s/he cries, I might spoil him/her" (to capture notions of developmentally appropriate care), and "At two weeks of age, babies cry for a specific reason" (to capture understanding of crying as normal infant behavior and not always a reflection on parental care).

Other questions asked the typical amount of time a baby cries $(<1$ hour, 1-2 hours, 2-3 hours, $>3$ hours) at ages 1 week and 7 weeks. Researchers computed the percentage of correct answers.

J Community Psychol. Author manuscript; available in PMC 2015 October 08. 
- Parental resilience: Participants at both follow up interviews rated their opinion (from "strongly disagree" to "strongly agree") on six statements about how they felt when they could not stop their baby's crying. Because these questions referred to situations where their baby cried or caused them parental stress, these measures were not administered at baseline. Item responses were scrutinized for underlying patterns via factor analysis, using default principal component analysis settings in SPSS, with Varimax rotation. This procedure generated two indexes with all items loading $>0.60$ on one factor and $<0.05$ on the other: self-blame (mean of: I feel helpless, I worry that I'm not a good enough parent, I wonder what I'm doing wrong, I just want to scream too) and self-reassurance (mean of: reminding oneself to take a deep breath, that this is only temporary).

- Social connection: Social connection was the total number of times in the past week participants reported asking for help, taking turns with a mate, or having a "go-to" person to manage stress when their baby cried. Because these questions referred to situations where the baby cried or caused parental stress, these measures were not administered at baseline.

TPB Mediators-The TPB posits that individuals will adopt recommended behaviors if they (a) have a favorable attitude toward the behaviors targeted in the intervention, i.e., perceive them as effective in promoting their infant's health (perceived effectiveness), (b) have confidence in their ability to carry out the behaviors in light of existing supports and obstacles (behavioral control), and (c) plan to do so (behavioral intent; Ajzen \& Fishbein, 1980). Researchers assessed three TPB mediators at all three time points. Ratings used 5point Likert-type scales ranging from 1 (not at all) to 5 (very)."

- Perceived effectiveness: Respondents indicated how well they thought each target behavior would work to calm their crying baby or to manage their own stress. Responses were averaged a across behaviors.

- Perceived behavioral control: Respondents indicated how sure they were that they could calm their baby and manage their own stress. This was a single item.

- Behavioral intention: Respondents indicated how likely it was that they would perform the target behaviors within the next four weeks. Responses were averaged a across behaviors.

Because internal consistency of the two indices (perceived effectiveness and behavioral intention) was limited, but not unacceptable (Cronbach's alpha $\sim 0.53$ ), individual items were also analyzed separately.

Covariates and process data-Basic demographic information was collected: age, race, His-panic/Latino ethnicity, marital/relationship status, education, and employment, as well as several factors that might influence outcomes: previous experience caring for an infant (from $1=$ none at all to $5=\mathrm{a}$ lot), perceived tolerance for hearing an infant cry (from $1=$ much less than most people to $5=$ much more than most people), and perceived crying by their own infant compared to perceived average (from $1=$ much less than average to $5=$ much more than average). Follow-up interviews asked the average amount of time spent 
with the infant and as the primary caregiver. All interviews asked about exposure to outside sources of information about similar topics.

\section{Analyses}

Quantitative comparisons were made between intervention and control participants based upon cohort/intent to treat. Preliminary analyses checked for demographic differences between groups, and between those who did and did not complete the study. Continuous outcomes were estimated initially by analysis of covariance regression models (Kleinbaum, Kupper, \& Morgenstern, 1982), controlling for parent's gender, race, employment status, prior experience caring for infants, and the child's current age, as well as the baseline measure of the outcome as covariates. Analyses were also repeated separately for the following subgroups: fathers, parents who reported that their infant cries more than average, parents who reported greater difficulty managing stress, parents of infants between 1 and 22 weeks old, and parents who spent $>30 \%$ time with the infant and at least some as the primary caregiver.

It was not feasible to analyze possible effects of site, due to an uneven distribution of participants between sites (30\% vs. $70 \%$ ), compounded by an uneven distribution of control versus intervention participants across sites (61\% controls at the smaller site vs. $45 \%$ controls at the larger site). These would leave the sample size with inadequate power to detect moderate differences between intervention and control participants. Although in three of the analyses, race or employment status proved significant, those findings did not alter the effect of the intervention. Since results were consistent across analyses, for ease of interpretation the results displayed are main effects, for the entire sample, without controlling for those variables, and the simpler statistics $\left(t\right.$ and $\left.\chi^{2}\right)$.

Analysis of parents' descriptions of their behavior employed well-recognized qualitative methods based on grounded theory. Data were organized into conceptual categories using the "constant comparative method"-an iterative process described by Glaser and Strauss (1967). Initial conceptual categories identified by the researchers and expert consultants were then constantly revised to reflect new categories that emerged from applying them to pilot data. To be as objective as possible in analyzing the results, the researchers used a "transcendent perspective," recommended by Lofland and Lofland (1984). Inter-rater reliability was established by having two researchers code randomly selected answers, comparing results and resolving discrepancies.

Upon completion of this process, researchers identified a comprehensive set of categories that reflected respondents' perceptions concerning the open-ended interview questions about their parental behavior. The categories were then applied to the open-ended interview responses, and findings within each category were then summarized in narrative form. 


\section{RESULTS}

\section{Participants}

The 423 parents who enrolled included 300 (71\%) fathers (or, in one case, the mother's nonpaternal male partner) and $123(29 \%)$ mothers. Table 1 reports the background characteristics of the participants.

Fathers in the study were more likely than mothers to be married (59\% vs. 39\%), employed ( $84 \%$ vs. $65 \%$ ), older (average age 29 vs. 26), and have less experience caring for infants (all $p<0.001$ ). Group comparisons at baseline revealed one demographic difference: More intervention participants were employed either full-time (70.8\% vs. $61.6 \%)$ or part-time, $13.7 \%$ vs. $10.9 \% ; \chi^{2}=8.99, p=0.01$. A total of $358(85 \%)$ completed the 5 -week interview and $326(77 \%)$ completed the 17-week interview. White participants were less likely than participants of other races to complete the study, $73.3 \%$ vs. $85.5 \% ; \chi^{2}=8.73, p=0.003$.

\section{Self-Reported Behavior}

Intervention participants' reports of strategies they used to calm their baby's crying did not differ from controls in the number or variety of appropriate strategies used. Nevertheless, in 5-week and 17-week interviews when intervention participants were asked about $\mathrm{ABC}$ (Table 2), of those who said they had looked at the media program or booklet, $70 \%$ and $72 \%$, respectively, reported that because of the intervention they had done something differently to calm their baby.

Qualitative analyses revealed 13 distinct strategies, the most common being swaddling and skin-to-skin holding. Other common answers were trying a variety of techniques, and trying techniques multiple times if a strategy did not work the first time.

The groups did not differ in the number of strategies used to manage parental stress when their baby cried. At 17 weeks, however, intervention participants reported using a wider variety of strategies than controls to manage parental stress $(2.3$ vs. $2.1, t=2.7, p<.01)$. Also, at the two follow-up interviews, $61 \%$ and $60 \%$ of intervention parents who had looked at the materials reported that because of the intervention, they had done something differently to manage their stress. Qualitative analyses revealed nine distinct actions, the most common being to get some distance from the baby, knowing that it's okay to let the baby cry or step away for a while, and asking for help from another person.

The intervention was well received. In particular, the DVD and in-hospital media were rated an average of over four out of five for helpfulness, and $96 \%$ of parents would recommend All Babies Cry to other parents.

\section{Strengthening Families Model Protective Factors (See Table 3)}

Knowledge of parenting and child development-At both follow-up interviews, intervention parents answered more knowledge questions correctly than did controls. Also, White parents had higher knowledge scores than non-White parents. 
Parental resilience-Intervention parents reacted to their baby's crying with more selfreassurance and, at the 17-week interview, reported less self-blame. Also, at both follow-ups White parents expressed more self-blame.

Social connections-Although quantitative results did not point to greater social connections in the intervention group, about a third of those who reported behavior change as a result of the program, in response to open-ended questions, cited asking family or friends for help, taking turns with their partner, or having a "go-to" person.

\section{Theory of Planned Behavior Mediators (See Table 3)}

Perceived effectiveness, behavioral control, and intent to calm infant crying-

At both follow-up interviews, intervention parents perceived the target strategies for calming their baby's crying to be significantly more effective than did control parents. The groups did not differ in perceived behavioral control of infant crying. Intervention parents were significantly more likely to express intent to implement the target behaviors.

\section{Perceived effectiveness, behavioral control, and intent to manage parental} stress-At both follow-up interviews, intervention parents perceived the target strategies for managing stress to be significantly more effective than control parents. The groups did not differ in perceived behavioral control of parental stress, although at both follow-up interviews, employed parents expressed less behavioral control than unemployed parents, and at 17 weeks White parents expressed greater behavioral control. Intervention parents were significantly more likely to express intent to implement the target behaviors.

\section{Covariates}

Results were similar when controlling for gender, race, employment status, prior experience with infants, and age of child. Results were also comparable for subgroups of fathers, parents whose infants cry more than average, parents who have more difficulty managing stress, parents of infants $>1$ and $<22$ weeks old, and parents who spend at least $30 \%$ of the time with the child and at least some as the primary caregiver.

\section{DISCUSSION}

Through extensive formative research - interviews of experts and parents, focus groups with the intended audience of young parents, some including only new or expectant fathers, and observation of group work with past perpetrators of domestic partner violence-we were able to design novel content around AHT prevention and a unique approach to the messaging. This formative research helped the developers to determine that a substantial portion of $\mathrm{ABC}$ should be devoted to helping parents recognize and alleviate their own stress during the newborn period. The resulting program was well received by intervention participants in the study, $71 \%$ of whom were fathers, with $96 \%$ stating they would recommend it to a friend or relative.

The results reported here, observed in first-time fathers and mothers of newborns, demonstrate that $\mathrm{ABC}$ is a promising approach for the promotion of family strengths and for teaching both parenting and parental stress skills. $\mathrm{ABC}$ appeared effective at enhancing 
specific mediators of behaviors relevant to AHT. Parents who received the ABC intervention surpassed control parents in two of the three targeted protective factors in the SFM: knowledge of parenting and child development and parental resilience. In addition, intervention parents attributed to $\mathrm{ABC}$ their use of social connections (the third targeted protective factor) to manage stress. These results will help ensure coordination with maltreatment prevention programs using the same SFM.

The $\mathrm{ABC}$ program and the evaluation reported here are the first to substantially address parental stress reduction in the context of education for new parents. ABC provides detailed descriptions of specific skills and portrays actual parents delivering and demonstrating content. Even though intervention parents did not use a greater number of stress management strategies than control parents, at 17 weeks they used a wider variety of such strategies and reported using stress-reduction strategies depicted in $\mathrm{ABC}$ because of the program. Thus, $\mathrm{ABC}$ 's broader aim of helping parents adopt healthy stress responses may also assist with the prevention of other forms of child maltreatment.

Although the two groups of parents did not differ in strategies they used to calm their crying baby, intervention parents surpassed control parents in two out of three TPB mediators of behavior: perceived effectiveness and behavioral intent. Intervention parents who viewed or read the $\mathrm{ABC}$ materials at home described using many of the recommended infant calming strategies as a result of the program materials.

\section{Strengths}

$\mathrm{ABC}$ directly addressed reduction of parental stress, complementing information about infant behavior and development and infant care-related skills. Both the program itself and the evaluation were firmly grounded in theory. The evaluation tested a real world implementation of $\mathrm{ABC}$ in two different birth hospitals in different states, using mixed methods. The evaluation design intentionally oversampled fathers, and findings were consistent for fathers when analyzed separately.

\section{Limitations}

Because AHT is relatively rare, the evaluation did not attempt to measure actual incidence, instead resting on mediating variables associated with risk factors. Larger epidemiological approaches will be necessary to evaluate maltreatment outcomes. The study used a delayed intervention design and individual participants were not randomly assigned. Thus, researchers could not account for any unmeasured secular changes that may have influenced study outcomes, and interviewers were aware of the group status of participants. Although the two sites represented different levels of nurseries, their geographic proximity limits generalizability of results outside the region. It was not feasible to analyze possible effects of site for reasons previously explained in the Analyses section. The measured effects were based on self-report items; intervention participants may have experienced social demand to report positive change. 


\section{CONCLUSIONS}

$\mathrm{ABC}$, designed for introduction in the postpartum hospital stay, is a promising educational program for first-time parents. This evaluation suggests that $\mathrm{ABC}$ successfully reaches fathers and supports the building of family-level protective factors. These findings warrant larger scale implementation and evaluation of the intervention to see if change in the mediators can change the ultimate outcome of reducing or eliminating the rare event of AHT.

Further exploration using larger populations that allow subgroup analyses and/or more indepth qualitative approaches are needed to better understand the extent to which specific intervention features contributed to the intervention's apparent effectiveness. Additional studies are necessary to compare its effectiveness with those of similar programs produced earlier.

\section{Acknowledgments}

This study was supported by a grant from the Eunice Kennedy Shriver National Institute of Child Health and Human Development, grant number R44HD061122.

Other than the partial salaried compensation received by Dr. Morrill, Ms. McElaney and Ms. Peixotto from NICHD grant number R44HD061122, the authors have no conflict of interest relevant to this article We acknowledge the contributions of the Massachusetts Department of Public Health, Women \& Infants Hospital (Providence, RI) and the Family Life Center for Maternity at Mercy Medical Center (Springfield, MA).

\section{References}

Ajzen, I. Theory of planned behavior diagram. 2006. Retrieved from http://people.umass.edu/aizen/ tpb.diag.html

Ajzen, I.; Fishbein, M. Understanding attitudes and predicting social behavior. Englewood Cliffs, NJ: Prentice Hall; 1980.

Alexander, S.; Mizelle, E.; Saul, J.; Jenkins, L.; Parks, S.; Valle, LA.; Klevens, J. Essentials for childhood: Steps to create safe, stable, and nurturing relationships. 2013. Retrieved from http:// www.cdc.gov/violenceprevention/pdf/efc-01-03-2013-a.pdf

Altman RL, Canter J, Patrick PA, Daley N, Butt NK, Brand DA. Parent education by maternity nurses and prevention of abusive head trauma. Pediatrics. 2011; 128(5):e1164-1172.10.1542/peds. 2010-3260 [PubMed: 22025587]

Barr RG, Barr M, Fujiwara T, Conway J, Catherine N, Brant R. Do educational materials change knowledge and behaviour about crying and shaken baby syndrome? A randomized controlled trial. Canadian Medical Associtation Journal. 2009; 180(7):727-733.10.1503/cmaj.081419

Barr RG, Rivara FP, Barr M, Cummings P, Taylor J, Lengua LJ, Meredith-Benitz E. Effectiveness of educational materials designed to change knowledge and behaviors regarding crying and shakenbaby syndrome in mothers of newborns: A randomized, controlled trial. Pediatrics. 2009; 123(3): 972-980.10.1542/peds.2008-0908 [PubMed: 19255028]

Barr RG, Runyan DK. Inflicted childhood neurotrauma: The problem set and challenges to measuring incidence. American Journal of Preventative Medicine. 2008; 34(4 Suppl):S106-S111.10.1016/ j.amepre.2008.01.021

Ceccato NE, Ferris E, Manuel D, Grimshaw JM. Adopting health behavior change theory throughout the clinical practice guideline process. Journal of Continuing Education in the Health Professions. 2007; 27(4):201-207. [PubMed: 18085640]

Daro, D.; Donnelly, AC. Child abuse prevention: Accomplishments and challenges. In: Myers, JEB.; Berliner, L.; Briere, J.; Hendrix, CT.; Jenny, C.; Reid, TA., editors. The APSAC handbook on child maltreatment. 2. Thousand Oaks, CA: Sage; 2002. p. 431-448.

J Community Psychol. Author manuscript; available in PMC 2015 October 08. 
Davies WH, Garwood MM. Who are the perpetrators and why do they do it? Journal of Aggression, Maltreatment \& Trauma. 2001; 5(1):41-54.

Dias MS, Smith K, DeGuehery K, Mazur P, Li V, Shaffer ML. Preventing abusive head trauma among infants and young children: A hospital-based, parent education program. Pediatrics. 2005; 115(4):e470-e477.10.1542/peds.2004-1896 [PubMed: 15805350]

Fang X, Brown DS, Florence CS, Mercy JA. The economic burden of child maltreatment in the United States and implications for prevention. Child Abuse \& Neglect. 2012; 36(2):156-165.10.1016/ j.chiabu.2011.10.006 [PubMed: 22300910]

Flaherty EG. Analysis of caretaker histories in abuse: Comparing initial histories with subsequent confessions. Child Abuse \& Neglect. 2006; 30(7):789-798.10.1016/j.chiabu.2005.12.008 [PubMed: 16844217]

Glaser, BG.; Strauss, AL. The discovery of grounded theory: Strategies for qualitative research. Chicago, IL: Aldine; 1967.

Goulet C, Frappier JY, Fortin S, Deziel L, Lampron A, Boulanger M. Development and evaluation of a shaken baby syndrome prevention program. Journal of Obstetric, Gynecologic, \& Neonatal Nursing. 2009; 38(1):7-21.10.1111/j.1552-6909.2008.00301.x

Horton, C. Protective factors literature review: Early care and education programs and the prevention of child abuse and neglect. Center for the Study of Social Policy; 2003. Retrieved from http:// www.cssp.org/reform/strengthening-families/resources/body/LiteratureReview.pdf

Kleinbaum, DG.; Kupper, LL.; Morgenstern, H. Epidemiologic research: Principles and quantitative methods. Belmont, CA: Lifetime Learning Publications; 1982.

Lofland, J.; Lofland, LH. Analyzing social settings: A guide to qualitative observation and analysis. 2. Belmont, CA: Wadsworth; 1984.

Lee C, Barr RG, Catherine N, Wicks A. Age-related incidence of publicly reported shaken baby syndrome cases: Is crying a trigger for shaking? Journal of Developmental \& Behavioral Pediatrics. 2007; 28(4):288-293.10.1097/DBP.0b013e3180327b55 [PubMed: 17700080]

National Center on Shaken Baby Syndrome. The period of purple crying: A new way to understand your baby's crying. Ogden, UT: National Center on Shaken Baby Syndrome; 2004.

National Center on Shaken Baby, Syndrome. The period of purple crying: Did you know your baby would cry like this?. Ogden, UT: National Center on Shaken Baby Syndrome; 2007.

National Conference of State Legislators. Shaken Baby Syndrom Prevention Legislation. 2012. Retrieved from http://www.ncsl.org/issues-research/human-services/shaken-baby-syndromeprevention-legislation.aspx

Midwest Childrens' Resource, Center, \& Junior League of Saint, Paul. Portrait of promise preventing Shaken Baby Syndrome. St. Paul: Midwest Children's Resource Center at Children's Health CareJunior League of St. Paul; 1995.

Midwest Childrens' Resource, Center, \& Junior League of Saint, Paul. Portrait of promise preventing Shaken Baby Syndrome. St. Paul: Midwest Children's Resource Center at Children's Health CareJunior League of St. Paul; 2005.

Riffenburgh RS, Sathyavagiswaran L. Ocular findings at autopsy of child abuse victims. Ophthalmology. 1991; 98(10):1519-1524. [PubMed: 1961637]

Schnitzer PG, Ewigman BG. Child deaths resulting from inflicted injuries: Household risk factors and perpetrator characteristics. Pediatrics. 2005; 116(5):e687-e693.10.1542/peds.2005-0296 [PubMed: 16263983]

Shonkoff, JP.; Phillips, D. National Research Council (U.S.) Committee on Integrating the Science of Early Childhood Development. From neurons to neighborhoods: The science of early child development. Washington, DC: National Academy Press; 2000.

Sinal SH, Petree AR, Herman-Giddens M, Rogers MK, Enand C, Durant RH. Is race or ethnicity a predictive factor in Shaken Baby Syndrome? Child Abuse \& Neglect. 2000; 24(9):1241-1246. [PubMed: 11057709]

Starling SP, Holden JR, Jenny C. Abusive head trauma: The relationship of perpetrators to their victims. Pediatrics. 1995; 95(2):259-262. [PubMed: 7838645]

Strengthening Families Illinois. Six protective factors that keep families strong. 2011. Retrieved from http://www.strengtheningfamiliesillinois.org/index.php/main/content/category/protective_factors

J Community Psychol. Author manuscript; available in PMC 2015 October 08. 
The Center for the Study of Social Policy. Six protective factors that keep families strong. 2011. Retrieved from http://www.strengtheningfamiliesillinois.org/index.php/main/content/category/ protective_factors

U.S. Department of Health and Human Services, Administration for Children and Families. Child maltreatment 2010. 2011. Retrieved from: http://www.acf.hhs.gov/programs/cb/stats_research/ index.htm\#can 


\begin{tabular}{|c|c|}
\hline Protective Factor: Original Language & Protective Factor: Everyday Language \\
\hline Enhance parental resilience & Be strong \& flexible \\
\hline Develop social connections & Parents need friends \\
\hline $\begin{array}{l}\text { Build knowledge of parenting and child } \\
\text { development }\end{array}$ & $\begin{array}{l}\text { Being a great parent is part natural and } \\
\text { part learned }\end{array}$ \\
\hline Offer concrete support in times of need & We all need help sometimes \\
\hline Foster social and emotional competence & $\begin{array}{l}\text { Parents need to help their children } \\
\text { Communicate }\end{array}$ \\
\hline Promote healthy parent-child relationships & $\begin{array}{l}\text { Give your children the love \& respect they } \\
\text { need }\end{array}$ \\
\hline
\end{tabular}

Figure 1.

Strengthening families approach family protective factors.

Note: Factors addressed by ABC are bold and highlighted.

Source: Strengthening Families Illinois. (2011). Six protective factors that keep families strong. Retrieved from http://www.strengtheningfamiliesillinois.org/index.php/main/ content/category/protective_factors. 


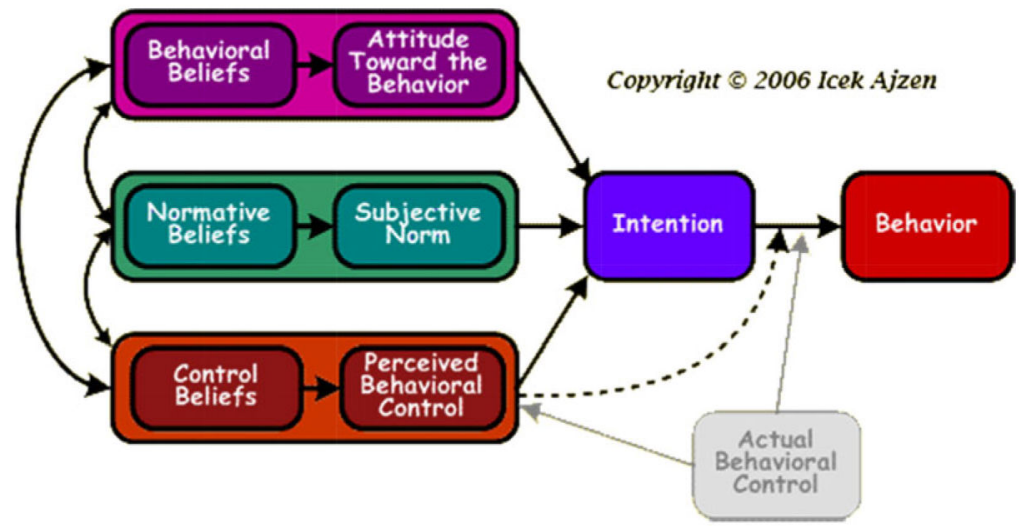

Figure 2.

Diagram of the theory of planned behavior.

Source: Ajzen, I. (2006). Theory of Planned Behavior Diagram. Retrieved from http:// people.umass.edu/aizen/tpb.diag.html.

Reprinted with permission from the author. 


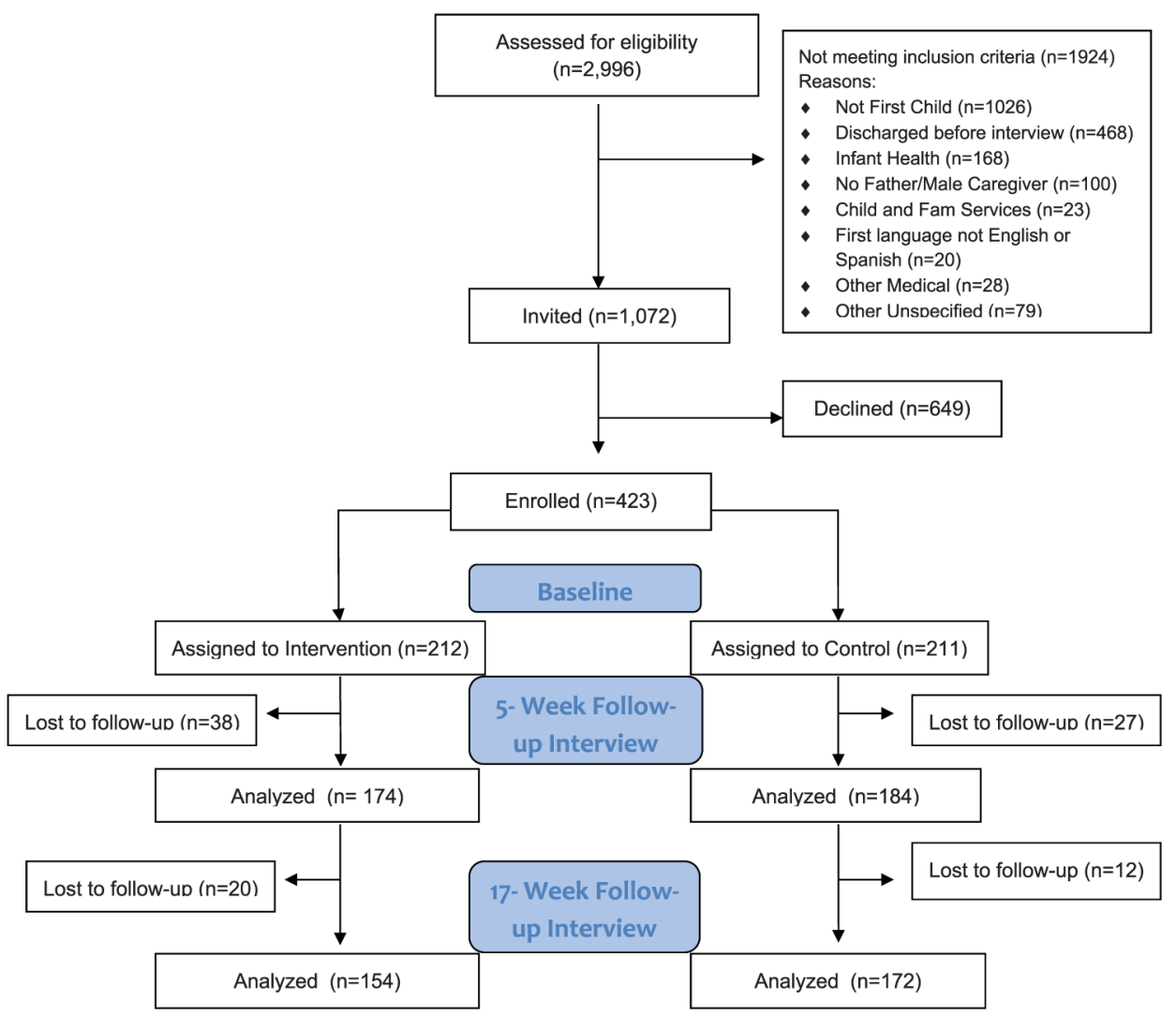

Figure 3.

CONSORT diagram.

Note: This was not a randomized trial; control group participants were recruited at each site prior to intervention (See text for details). 


\begin{tabular}{|l|l|}
\hline Target behaviors to calm infant: & Target behaviors to manage stress: \\
\hline Swaddle & Breathe deeply \\
\hline Skin-to-skin contact & Get some distance from the baby \\
\hline Offer a pacifier & $\begin{array}{l}\text { Remind yourself that it's normal to feel } \\
\text { frustrated }\end{array}$ \\
\hline Put the baby in a front carrier or sling & Ask family or friends for help \\
\hline Massage & Have a "go-to" person \\
\hline White noise or sound of appliances & \\
\hline Make funny sounds or faces & \\
\hline
\end{tabular}

Figure 4.

ABC behaviors selected for evaluation purposes. 


\section{Table 1}

Characteristics of Participants.

\begin{tabular}{lccc}
\hline & \multicolumn{2}{c}{$(\mathbf{n = 4 2 3})$} \\
\cline { 2 - 4 } Parent at baseline & $\%$ & $(\mathbf{n})$ \\
\hline Father (including one male caregiver not the father) & 70.9 & $(300)$ \\
Intervention Condition & 50.1 & $(212)$ \\
Hispanic or Latino/a: & 22.2 & $(94)$ \\
Race: Black/African American & 6.6 & $(28)$ \\
Race: White & 61.0 & $(258)$ \\
Married & 52.8 & $(223)$ \\
Education beyond HS & 65.0 & $(275)$ \\
Employed & 78.5 & $(52)$ \\
\hline & & Mean & $(S D)$ \\
\hline Age & $15-78$ & 28.1 & $(7.4)$ \\
Experience caring for infants & 2.6 & $(1.4)$ \\
Tolerance for crying & $1-5$ & 4.0 & $(0.9)$ \\
\hline Parent and child at 5-week interview (n= 358) & & \\
\hline Percent time as primary caregiver & $0-100$ & 42 & $(31)$ \\
Parent "reached limit" since birth & & 3.6 & $(11.3)$ \\
Parent "reached limit" last week & & 1.1 & $(2.5)$ \\
\hline & & 47 & $(168)$ \\
\hline Own baby cries less than average & & $(n)$ \\
\hline
\end{tabular}

Note. $\mathrm{SD}=$ standard deviation. 

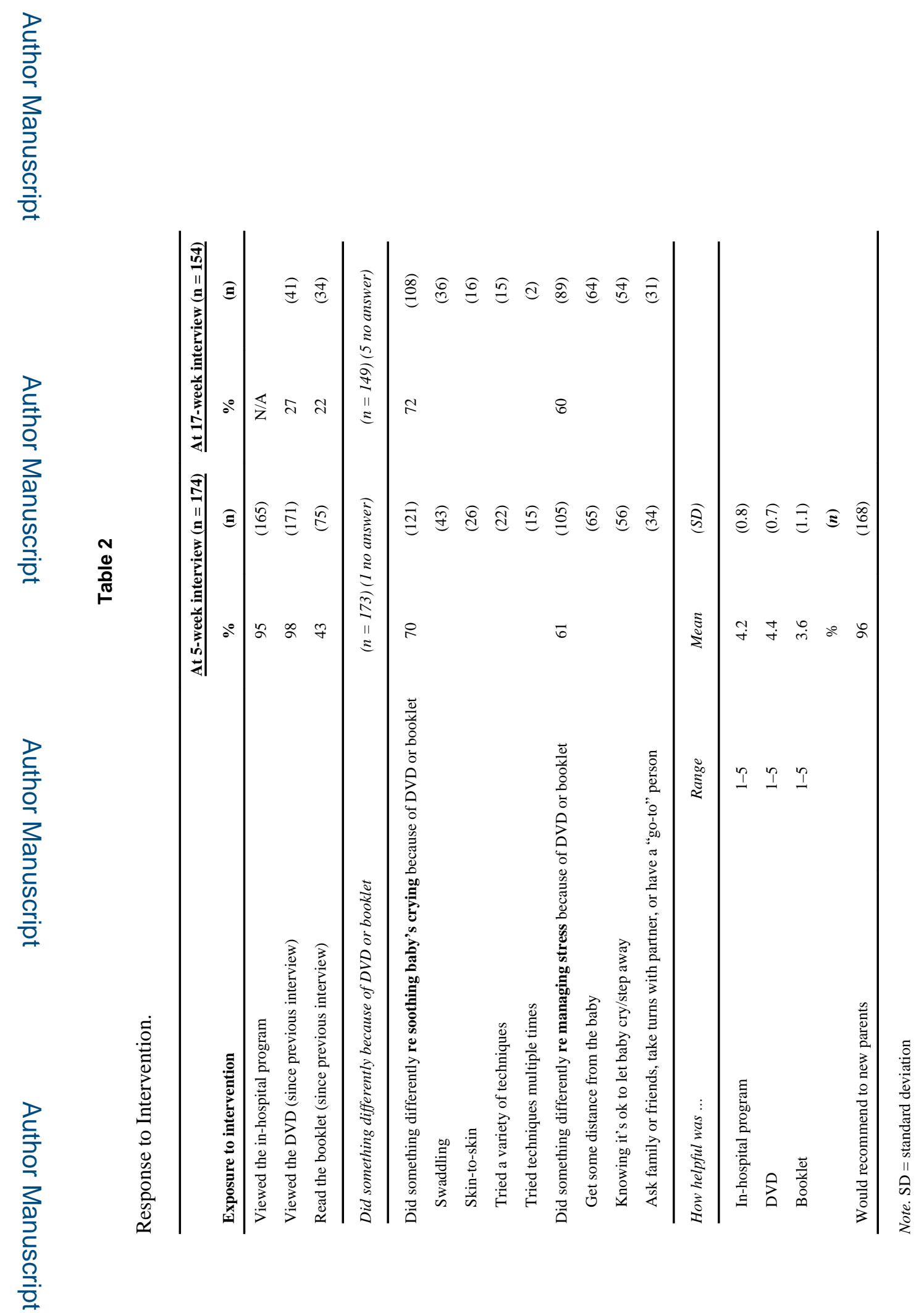

J Community Psychol. Author manuscript; available in PMC 2015 October 08. 


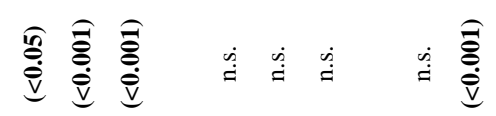
ثंن

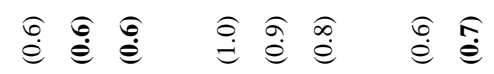

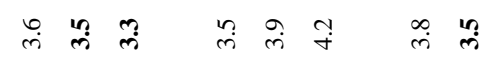

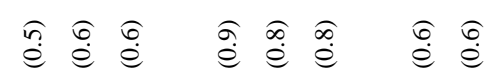

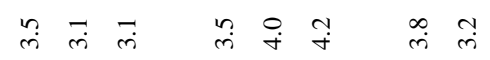




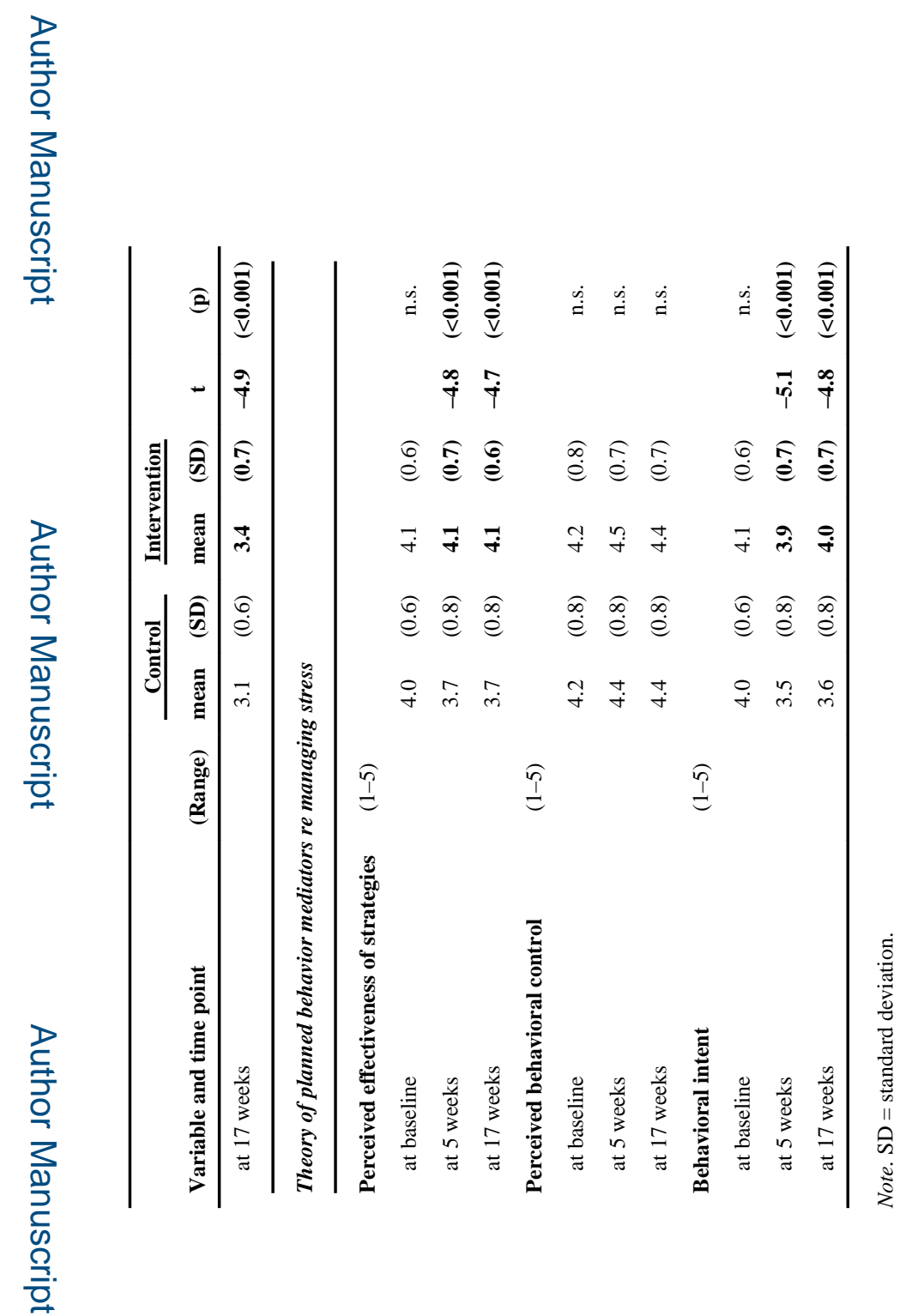

